\title{
The Role of Syntactic Obligatoriness in the Production of Intonational Boundaries
}

\author{
Duane Watson \\ University of Illinois at Urbana-Champaign
}

\author{
Mara Breen and Edward Gibson \\ Massachusetts Institute of Technology
}

\begin{abstract}
Researchers have hypothesized that words that are highly related semantically are more likely to occur within the same intonational phrase (F. zzaq; 1988; E. O. Selkirk, 1984). D. Watson and E. Gibson (2004) proposed that semantic closeness can be captured by using the argument/adjunct distinction, such that intonational boundaries are more likely to occur before adjuncts than before arguments. In the current experiment, the authors compared two aspects of argumenthood: semantic relatedness and obligatoriness. In a production study, speakers were more likely to place an intonational phrase boundary between a word and a dependent if the dependent was optional (e.g., after "investigation" in "The reporter's investigation [of the crash] unnerved the officials") than if the dependent was obligatory (e.g., after "investigated" in "The reporter investigated [the crash], and this unnerved the officials"). These data suggest that obligatoriness is a better predictor of intonational boundary placement than semantic closeness.
\end{abstract}

Keywords: intonational boundaries, prosody, language production, syntax

There has been a great deal of interest in the role of prosody in language production and comprehension (for a review, see Cutler, Dahan, \& Van Donselaar, 1997). This interest stems from the fact that prosody serves as a vehicle for pragmatic, discourse, and syntactic information, making it important for successful communication. In this article, we investigated factors that determine how speakers segment speech into prosodic units. Specifically, we investigated where speakers place intonational phrase boundaries. Intonational phrase boundaries are perceptually defined breaks in an utterance that are typically signaled by a pause, a change in pitch, and/or lengthening of the preboundary word (for a review, see Shattuck-Hufnagel \& Turk, 1996). Boundaries may occur, for example, in the locations indicated by "//" in (1):

1a. The reporters at a press conference following a scandal // were frustrated by the politician's answers to their questions.

1b. One journalist asked the same question three different ways // but the politician avoided the issue repeatedly.

1c. Eventually // a journalist asked a question that the politician answered.

Duane Watson, Department of Psychology, Beckman Institute for Advanced Science and Technology, University of Illinois at Urbana-Champaign; Mara Breen and Edward Gibson, Department of Brain and Cognitive Sciences, Massachusetts Institute of Technology, Cambridge, Massachusetts.

This project was supported by National Science Foundation Grant BCS-0218605, "Intonational Boundaries in Sentence Production and Comprehension."

Correspondence concerning this article should be addressed to Duane Watson, Department of Psychology, Beckman Institute for Advanced Science and Technology, University of Illinois at Urbana-Champaign, 603 East Daniel Street, Champaign, IL 61820. E-mail: dgwatson@uiuc.edu
An intonational boundary can occur between parts of a clause, as in 1a, or between clauses, as in 1b. A boundary can even occur after the production of only one word, as in 1c.

Although speakers have a great deal of flexibility in where they choose to place intonational boundaries, boundaries tend to be produced in certain locations with a great deal of regularity. Previous work has investigated the nature of these regularities and the degree to which they are influenced by syntactic structure (Cooper \& Paccia-Cooper, 1980; F. Ferreira, 1988; Gee \& Grosjean, 1983; Schafer, 1997; Selkirk, 1984; Watson \& Gibson, 2004). Models (such as those developed by Cooper \& PacciaCooper, 1980; F. Ferreira, 1988; and Gee \& Grosjean, 1983) predict where intonational boundaries ${ }^{1}$ are most likely to be produced in a sentence on the basis of a given syntactic structure. Despite being quite successful at predicting intonational boundary placement, these models have a number of shortcomings. They have a large number of steps and parameters, and they require theory-specific syntactic machinery to make predictions. Watson and Gibson (2004) have argued that the success of these models can be attributed to two common underlying principles that are related to processes in sentence production: planning and recovery. Watson and Gibson have argued that intonational boundaries provide the speaker with time to (a) plan the properties of upcoming

\footnotetext{
${ }^{1}$ Cooper and Paccia-Cooper's (1980) and Gee and Grosjean's (1983) models were designed to predict the size of pauses between words, but more recent work suggests that the presence of a pause is just one of many factors that determine the percept of a boundary (Beckman \& Pierrehumbert, 1986) and that pause size correlates with intonational boundary placement and local segmental information rather than syntactic structure (F. Ferreira, 1993). In light of more current findings, we discuss these models as predictors of intonational boundary placement rather than pause size.
} 
linguistic structure and (b) recover from expending resources after producing complex linguistic structure. Thus, Watson and Gibson predicted that intonational boundaries are most likely to occur before and after long constituents because these locations are likely points for planning and recovery. Watson and Gibson found that a model based on these principles performed as well, and sometimes better, than previous, more complicated models in predicting intonational phrases.

However, syntactic constituent length is not the only factor that determines boundary placement. Watson and Gibson (2004) noticed that the status of the argument versus adjunct $/$ modifier $^{2}$ relationship between a head and its dependent may also affect the likelihood of producing an intervening intonational boundary. In sentences such as (2), speakers almost never placed an intonational boundary between a verb and its direct object, an argument (e.g., between ignored and the judge), even if the direct object was comparatively long. In contrast, speakers consistently placed intonational boundaries between nouns and adjunct relative clauses that followed them (e.g., between judge and who fired the secretary). ${ }^{3}$

2. The reporter ignored the judge who fired the secretary.

Although there is no clear-cut way to distinguish arguments from adjuncts, roughly, an argument is a phrase that fulfills a semantic requirement of a lexical head (for tests for argumenthood, see Schütze \& Gibson, 1999). One test for argumenthood is obligatoriness. If the dependent of a lexical head is obligatory, then it is an argument. (However, note that there are arguments that are not obligatory.) For example, the judge is an argument of ignored in (2) because the verb ignored requires an entity referring to the thing that is ignored. In contrast, the relative clause who fired the secretary is syntactically and semantically optional material: It tells us more information about the judge, but it is not lexically required by the head noun judge. Because this phrase is not a semantic requirement of its lexical head judge, it is an adjunct rather than an argument.

Watson and Gibson (2004) hypothesized that argument relations restrict effects of length on intonational boundary placement. Specifically, Watson and Gibson proposed that a head and its immediately following argument are likely to be planned at the same time because of the tight semantic link between heads and their arguments. Thus, there is a close to zero likelihood for a boundary following a head and before its first argument, independent of the size of the argument. In contrast, an adjunct is not necessarily planned at the same time as its head, and thus the size of an adjunct can affect the likelihood of producing a boundary before it. Thus, in (2), the likelihood of an intonational boundary between ignored and the judge is unlikely to be influenced by the size of the upcoming relative clause the judge who fired the secretary because the complex noun phrase (NP) is an argument of ignored. In contrast, the probability of a boundary occurring between judge and who should be affected by the length of the upcoming relative clause who fired the secretary because the relative clause is an adjunct of the noun judge. The longer the adjunct is, the more likely it is that a boundary will occur before it.

F. Ferreira (1988) was one of the first to hypothesize that the production of intonational boundaries was affected by whether a phrase was an argument or an adjunct of a preceding head. She proposed that intonational boundary production is a function of the word boundary's location in an X-bar representation of a sentence, which instantiates argument relationships in its syntactic structure (Jackendoff, 1977). She argued that arguments are less likely to be preceded by an intonational boundary than adjuncts, continuing work by Selkirk (1984), who claimed that semantic relationships play a key role in restricting which words are grouped together into intonational phrases.

Links between planning, argumenthood, and intonational phrasing depend on two assumptions about production: (a) sentence planning is incremental and occurs at intonational boundaries, and (b) planning units are partly based on semantic structure. A great deal of evidence suggests that language production is at least partly incremental (V. S. Ferreira, 1996; Levelt, 1989; Wheeldon \& Lahiri, 1997). In current models of language production, incrementality is implemented through compartmentalized systems that process information in parallel. Information is processed initially at the message level. After processing is complete, the information is passed down to lemma and lexical retrieval processes, which in turn pass the information on to phonological and articulatory processes (Levelt, 1989). A consequence of this architecture is that processing at each level can occur in parallel and over different domains, which allows speakers to plan a sentence as they produce it. For example, a speaker might have only accessed a few words at the phonological level but may have fully completed processing at the message level. Because parts of the planning system run in parallel over different domains, a sentence can be initiated before planning at all levels is complete (Bock \& Levelt, 1994; Levelt, 1989). Watson and Gibson (2004) proposed that intonational boundaries provide speakers with midsentence stopping points for planning while the sentence is underway. This need for planning time is consistent with results showing that initiation times for sentences are longer when sentences contain long or syntactically complex subjects (F. Ferreira, 1991; Wheeldon \& Lahiri, 1997). Intonational boundaries might provide this time for planning.

If one assumes that planning occurs at intonational boundaries, a preference for producing semantically related words within the same intonational phrase may indicate that semantically related words are planned at similar points in the production system. Whether semantic units correspond to planning units is an open question. Researchers have argued that major syntactic phrases such as clauses, NPs, and verb phrases serve as basic planning units (Ford, 1982; Garrett, 1976; Holmes, 1988; Meyer, 1996); however, these also correspond to semantic units such as referents and events. The production system may use semantic structure as an additional domain of planning. Support for this comes from work by Solomon and Pearlmutter (2004), who found that words

\footnotetext{
${ }^{2}$ The terms adjunct and modifier are often used interchangeably to describe nonargument dependents. We use the term adjunct in this article.

${ }^{3}$ The explanation for this observation is complicated by the fact that the presence of an intonational boundary before a relative clause is a cue that it is nonrestrictive rather than restrictive (Watson \& Gibson, 2004). However, Watson and Gibson (2004) found that speakers still often produced a boundary between the head noun and a restrictive relative clause in a context supporting a restrictive interpretation. Thus, the presence of a boundary is compatible with both restrictive and nonrestrictive interpretations of relative clauses.
} 
that are semantically related at a conceptual level, as heads and arguments tend to be, elicit more verb agreement errors than words that are less semantically integrated. In a continuation task, participants were asked to produce the examples in (3) as the subjects of a complete sentence.

3a. The drawing of the flowers

3 b. The drawing with the flowers

Solomon and Pearlmutter (2004) found that there were more agreement errors between the generated verb and the head noun in 3a than 3b. In 3a, drawing and flowers are more semantically integrated than in $3 \mathrm{~b}$. Solomon and Pearlmutter proposed that this difference is due to the interactive, parallel nature of the production mechanism. Because the system operates in parallel, it is difficult to keep representations that are semantically related distinct, potentially creating agreement errors. Of relevance here is the notion that highly integrated material may overlap in planning. Arguments are typically more semantically integrated with their heads than adjuncts, which may mean that they are planned at the prehead intonational boundary. ${ }^{4}$

These data suggest that some aspect of the semantic relationship between a dependent and its head may affect whether a head and its dependent will be produced in a single intonational phrase. There are at least three possible ways to characterize the semantic relationship between head and dependent to account for the available evidence. One possibility is Watson and Gibson's (2004) hypothesis: that the relevant division is the argument/adjunct distinction. At the heart of this notion is that semantically related material is made available to the production system at the same time and is therefore planned together. Because arguments are more semantically related to their head than adjuncts, arguments will be more likely to be produced within the same intonational phrase as their heads.

Another possibility is that some component of the argument/ adjunct distinction is the relevant semantic division. The possibility that we explore here is based on the obligatoriness of the dependent. Under this hypothesis, obligatory dependents and their heads are more likely to be produced within the same intonational phrase than optional dependents and their heads. Watson and Gibson's (2004) observation that boundaries occurred less frequently between verbs and their direct objects than between nouns and their relative clause modifiers is consistent with either of these hypotheses. In particular, the difference in boundary production could be attributed to either the difference in argument/adjunct status of the two dependents-the semantic closeness of the two- or the difference in obligatoriness of the dependent relationship in each.

A third possibility, one that is quite different from the one that Watson and Gibson (2004) pursued, is that there is some other difference between the verb-NP and the noun-relative-clause dependencies that is responsible for the different sensitivity to the length of the dependent phrase (NP argument vs. clausal adjunct). For example, the category of the dependent-NP versus full clause-differs in this comparison. Some factor such as this may be responsible for the observed intonational boundary production differences.

In this article, we investigated the hypotheses that the argumenthood (semantic closeness) and/or obligatoriness of the dependent were factors that contributed to the observed boundary- placement differences between verb-NP and noun-relative-clause dependency relations. As mentioned above, one property of arguments is that they are often obligatory. However, in English, this is only true for arguments of verbs. Arguments of nouns are always optional (Grimshaw, 1990), as can be seen in a completion of the subject sentence fragments in (3), below in (4):

$4 \mathrm{a}$. The drawing of the flowers was an example of ambiguous representations.

4b. The drawing was an example of ambiguous representations.

Thus, one way to evaluate the argument/adjunct hypothesis against the obligatory/optional hypothesis is to compare the production of (a) verbs and their NP arguments (which are often obligatory) and (b) nominalized (or gerundive) forms of these verbs and their corresponding prepositional phrase (PP) arguments (which are always optional). We elaborate on this experimental design below.

To directly investigate the relationship between constituent relationships and intonational phrasing, we designed a production experiment to test three hypotheses. The first hypothesis is Watson and Gibson's (2004) hypothesis: that argumenthood/semantic closeness plays a role in determining intonational boundaries. If arguments are planned at similar points in time as their heads, then there will be fewer intonational boundaries between heads and arguments than between heads and adjuncts, independent of the category of the head (noun or verb).

The second hypothesis is that obligatoriness plays a role in determining intonational boundaries. Under this hypothesis, intonational boundaries occur less frequently following a head that obligatorily requires an argument than following a head that only optionally requires one. To test this possibility, we investigated whether there were differences in boundary placement between verbs and their obligatory arguments and nouns and their nonobligatory arguments. The obligatoriness hypothesis predicts more boundaries between head nouns and their arguments compared with head verbs and their arguments, contrary to the semanticcloseness account. ${ }^{5}$

A third hypothesis is that part of speech is the critical factor. It is possible that intonational phrase boundaries occur more often after nouns than verbs, independent of the argument status of the dependent, perhaps because verbs and their dependents are closer syntactically than nouns and their dependents. This hypothesis is consistent with both Nespor and Vogel's (1986) claim that intonational phrase boundaries only occur after nouns and with Watson and Gibson's (2004) original findings. Finally, it is possible that argumenthood, part of speech, and obligatoriness all

\footnotetext{
${ }^{4}$ See Solomon and Pearlmutter (2004) for discussion of some cases in which certain kinds of arguments are less semantically related to their heads than certain adjuncts.

${ }^{5}$ The direct object of a verb is often obligatory, and in most syntactic theories, it also enjoys a closer syntactic relationship with its head than the argument of a noun. The comparison between noun and verb arguments in the current experiment does not allow us to dissociate whether the relevant constraint is obligatoriness or some other aspect of the syntactic structure. Crucially, however, the predictions of the obligatoriness hypothesis differ from those of the semantic closeness hypothesis.
} 
contribute independently to intonational phrase boundary placement.

Word category and dependent type were manipulated to test the three hypotheses. Items such as (5) were tested. In all of the conditions, the critical position where we looked for an intonational boundary followed the underlined heads in $5 \mathrm{a}-5 \mathrm{~h}$ and preceded the bracketed dependent.

5: Verb conditions

5a. Argument, short:

The reporter investigated [the crash] and this unnerved the officials.

5b. Argument, long:

The reporter investigated [the crash of the subway] and this unnerved the officials.

5c. Adjunct, short:

The reporter arrived [after the crash] and this unnerved the officials.

5d. Adjunct, long:

The reporter arrived [after the crash of the subway] and this unnerved the officials.

5: Noun conditions

5e. Argument, short:

The reporter's investigation [of the crash] unnerved the officials.

5f. Argument, long:

The reporter's investigation [of the crash of the subway] unnerved the officials.

5g. Adjunct, short:

The reporter's arrival [after the crash] unnerved the officials.

5h. Adjunct, long:

The reporter's arrival [after the crash of the subway] unnerved the officials.

If the semantic closeness hypothesis is correct, such that speakers do not tend to place boundaries between heads and arguments (as proposed by Watson \& Gibson, 2004), then speakers will place fewer boundaries after the heads in $5 \mathrm{a}-5 \mathrm{~b}$ and $5 \mathrm{e}-5 \mathrm{f}$ than after the heads in $5 \mathrm{c}-5 \mathrm{~d}$ and $5 \mathrm{~g}-5 \mathrm{~h}$ because the bracketed dependents in the former conditions are arguments.

If the obligatoriness of the dependent affects boundary production, then there should be fewer boundaries after the heads in $5 a-5 b$, because their dependents are obligatory, compared with any of the other conditions, because the dependent is syntactically optional in these cases. Thus, the obligatoriness hypothesis predicts an interaction between argumenthood and syntactic type. To further test the predictions of this hypothesis, we conducted a survey to determine the degree to which naïve participants rated the completeness of the lexical heads without the dependents in the tested items. If the obligatoriness of a constituent plays a role in boundary placement, then participant ratings of head-dependent completeness should be inversely correlated with the likelihood of producing intonational boundaries for the same items.

Finally, if speakers place more boundaries after nouns than after verbs (Nespor \& Vogel, 1986), then more boundaries will be produced after the heads in conditions $(5 \mathrm{e}-5 \mathrm{~h})$ than conditions (5a-5d).

A third factor - the length of the argument/adjunct constituentwas also manipulated to test the three hypotheses in another way. Recall that Watson and Gibson (2004) found that speakers did not place boundaries between direct objects and verbs, regardless of how long the direct object was. This result could be explained by one of the three proposed hypotheses, such that direct objects are planned with their head verbs, independent of length. If argumenthood is the critical factor, then the argument conditions should not show length effects, resulting in an interaction between length and dependency type. If obligatoriness is the critical factor, then the verb-argument condition should not show length effects, resulting in a three-way interaction among the factors. If part of speech is the critical factor, then the verb conditions should not show length effects, resulting in an interaction between length and part of speech.

Thus far, we have discussed the predictions of the three hypotheses with respect to the likelihood of producing intonational boundaries at one position in a sentence: between the underlined heads in (5) and their following dependents. However, recent evidence suggests that intonational boundary placement may be influenced by the location of other boundaries in a sentence (Frazier, Clifton, \& Carlson, 2004). Thus, a potential concern with localizing our analyses to one position is that the manipulated factors in the study may also have effects on other sentence positions, making observed differences at the target position difficult to interpret. To address this concern, we measured intonational boundary placement immediately before the head as a control. This location was chosen for two reasons. First, it is very close to the boundary of interest. If the placement of intonational boundaries interact in some way, then one might expect the interaction to occur with respect to potential boundary locations that are close together. Second, for phonological reasons, intonational boundaries are more likely to follow a word with lexical content than a function word (Gee \& Grosjean, 1983; Watson \& Gibson, 2004). The prehead boundary is the only word boundary that follows a content word before the region of interest, making it a potential location for intonational boundary placement and a useful point of comparison.

\section{Method}

\section{Participants}

Twenty-four pairs of English speakers from the Massachusetts Institute of Technology community participated in the study for $\$ 10$ each.

\section{Materials and Design}

Part of speech (noun, verb), argumenthood (argument, adjunct), and syntactic length (long, short) were manipulated in a $2 \times 2 \times 2$ design. Thirty-two stimulus sets similar to (5) were constructed. Part of speech was manipulated so that the matrix subject of the sentence was either followed by a verb (e.g., the reporter investigated) or by a nominalized or gerund form of the verb (e.g., the reporter's investigation; the committee's wavering). The gerund was included in cases in which the verb had no nominalized form or if the meaning of the nominalized form in the target sentence differed from the meaning of the verbal form in the verbal conditions. Nominalized forms were used in most items: 52 of the 64 noun forms across the items. (Note that there are two different noun-verb forms for each item. Thus there were $2 \times 32=64$ noun-verb pairs across the items.) Argumenthood was manipulated so that the dependent following the head was either an argument or an adjunct of the verb or nominal/ gerund form (e.g., investigated the crash/arrived after the crash). The arguments were all obligatory NP arguments of the head verbs. The 
adjuncts were all adjuncts according to the ordering and iterativity tests of adjuncthood from Schütze and Gibson (1999). The lexical head varied between the argument and adjunct conditions within items to manipulate the syntactic requirements in the verb conditions. The verbs in the argument conditions required a direct object, whereas those in the adjunct conditions did not. The third factor-length - was manipulated so that in half of the trials the argument/adjunct clause was lengthened by a PP (e.g., of the subway). This continuation did not change the meaning of the sentence substantially. The complete crossing of these three factors resulted in eight versions of each sentence. A complete list of stimuli is provided in the Appendix.

Note that the manipulation of part of speech is partially confounded with small variations in sentence length between conditions. The syntax of English often requires arguments of nouns to be preceded by the preposition "of," which is relatively short phonologically. The prepositions in the adjunct conditions were generally temporal prepositions like "after" and "before," which have more syllables and content than "of." Furthermore, adjuncts of verbs must be preceded by a preposition (e.g., The reporter arrived after the crash), whereas arguments of verbs have no such requirement (e.g., The reporter investigated the crash). As a result, the adjunct conditions were slightly longer than the argument conditions. There were also differences in length between the verb and noun conditions because nominalized and gerund forms of the verb are usually longer than their source verbs (e.g., investigate vs. investigation). Finally, because different verbs and nouns were used in the argument and adjunct conditions, these conditions had small differences in syllable length.

Although each of the differences observed above may play some role in intonational phrasing, previous research suggests that the number of prosodic words, or content words, in a sentence plays a more significant role in planning constituents. For example, Wheeldon and Lahiri (1997) found that the initiation time for a sentence depends on the number of prosodic words in the subject, which were matched across conditions in this study. It is therefore unlikely that the small differences in syllable length across conditions in our experiment had much effect.

It should also be noted that all of the experimental items included temporary ambiguities that were resolved by world knowledge within the items. For example, the second preposition in the long conditions (e.g., for in [6] below) can modify either the immediately preceding noun or the preceding verb:

6. The examiner postponed the interview for graduate school and this distressed the candidate.

The temporary PP-attachment ambiguity is disambiguated by the content of the NP graduate school, biasing toward an interpretation in which the interview for graduate school is a constituent. Furthermore, encountering the conjunction and following the NP-Verb-NP-PP sequence results in another temporary ambiguity because the conjunction can conjoin with either of the preceding NPs (the interview and graduate school in [6]), the preceding clause (the target attachment site), as well as other possible attachment sites. This ambiguity was always resolved by the content of the conjoining element at the latest (e.g., the clause this distressed the candidate in [6]).

Although studies have shown that ambiguity can interact with boundary placement (e.g., Cutler et al., 1997), the presence of these temporary ambiguities did not present a confound in the current study because (a) all sentences were disambiguated well before their conclusions and (b) the speakers had as much time as they wanted to read each sentence to themselves before they produced it. Thus, the speakers presumably had the target structure in mind when they spoke the sentences. Furthermore, the speakers had to answer a comprehension question about a sentence that they produced, thereby demonstrating that they had a correct understanding of each sentence before they produced it. In any case, the interactions that we observed between length and argument status (see the Results section) are not explained by ambiguity differences among the conditions.
The materials were presented in a Latin Square design, resulting in eight lists. Each list was presented in a random order. There were also 44 fillers, comprising items from two other unrelated experiments, with different syntactic structures.

\section{Procedure}

We conducted the experiment using Linger, a software platform for language processing experiments. ${ }^{6}$ Two participants were included in each trial. One participant was the speaker, and the other was the listener. Both the speaker and listener were present in the same room for the study, at separate computers such that they could not see each other's computer screens. All instructions were given to each participant on the computer screen in front of him/her, so neither participant was privy to the instructions that the other participant received. Before the study began, the speakers were told that they would be producing sentences for their partners (the listeners), and the listeners would be required to answer a comprehension question about each sentence immediately after it was produced. Each trial began with the speaker being presented with a sentence on the computer screen to read silently until she/he understood it. The speaker then answered a true-or-false content question about the sentence, to ensure understanding. If the speaker answered correctly, she/he proceeded to produce the sentence out loud once. If the speaker answered incorrectly, she/he was given another chance to read the sentence and to answer a different question about it. For example, after the speaker read "The reporter investigated the crash and this unnerved the officials," the question "Did the reporter investigate the crash?" appeared. If the speaker answered incorrectly, she/he would read the sentence again and then see: "Were the officials relieved?" The number of "true" and "false" answers was balanced across items, as was the part of the sentence to which the question referred. The speaker always produced the sentence after the second question whether she/he got the second question right.

The listener sat at another computer and saw a blank screen while the speaker went through the procedure described above for each sentence. After the speaker produced a sentence out loud for the listener, the listener would then press the space bar on his/her computer, whereupon he/she was presented with a true-or-false question about the content of the sentence that was just produced. Listeners were provided feedback when they answered a question incorrectly.

Each sentence was recorded digitally and analyzed with the PRAAT program. ${ }^{7}$ Each production was coded for intonational boundaries by two research assistants who were naïve to the goals of the study. Each of the coders marked the strength of a boundary using the following break indices: $4=$ intonational boundary, $3=$ intermediate phrase boundary, $1=$ normal word boundary, $\mathrm{P}=$ hesitation pause, and $\mathrm{D}=$ disfluency. Because of their perceptual similarity, intonational boundaries (4) and intermediate phrase boundaries (3) were collapsed in the analysis below.

The intonational boundary coding was consistent with the results of an acoustic analysis. Three subjects were excluded from the acoustic analysis because they did not produce any boundaries at the critical word boundary, and a within-subjects analysis is critical for controlling for between-subjects variability in speech. The length of the pause at word boundaries that were coded as intermediate or intonational phrase boundaries were longer $(75 \mathrm{~ms})$ than the pause at word boundaries that were not coded as intermediate or intonational boundaries $(22 \mathrm{~ms}), F_{1}(1,20)=11.60, p<.01 ; F_{2}(1,31)=61.35, p<.001$. It was not possible to compare the durations of the preboundary words in conditions that were coded as having an intonational or intermediate boundary

\footnotetext{
${ }^{6}$ Linger was written and designed by Doug Rohde and can be downloaded at http://tedlab.mit.edu/ dr/Linger/

${ }^{7}$ Available from Paul Boersma and David Weenink at http://www praat.org
} 


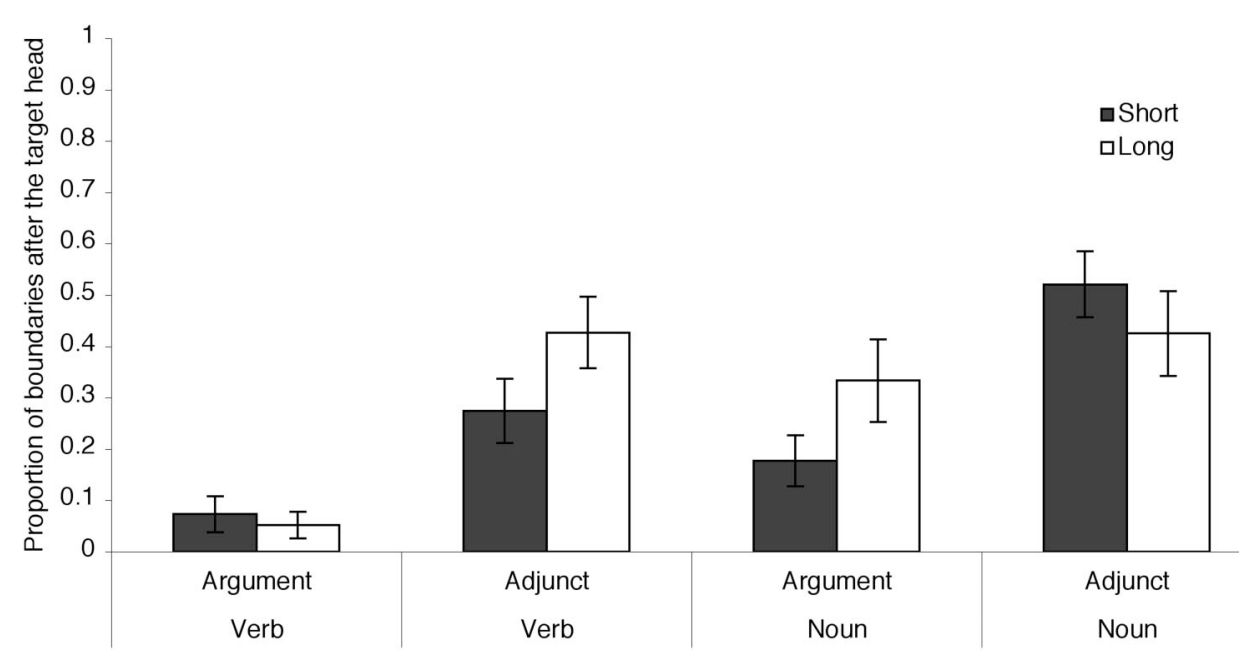

Figure 1. The proportion of intonational boundaries that immediately followed the head verb/noun when the dependent of the head was an argument or adjunct. Error bars indicate the standard error of the mean.

and those that did not because of segmental differences across utterances. However, the data from the average pitch on the preboundary word were consistent with the coding. Words that were followed by an intermediate or intonational phrase boundary had a lower average pitch $(170 \mathrm{~Hz})$ than those not followed by this type of boundary $(180 \mathrm{~Hz}), F_{1}(1,20)=14.48, p<.01$; $F_{2}(1,31)=16.37, p<.001$.

We measured reliability between coders by calculating the proportion of the instances in which the two transcribers agreed on the label of a word boundary using the method described by Pitrelli, Beckman, and Hirschberg (1994). This was calculated after the intermediate and intonational phrase boundaries were collapsed. The reliability for the entire data set was $88.4 \%$. Because overall reliability was high, the entire data set of one coder was used for analysis.

\section{Survey}

Eighty English speakers from the Massachusetts Institute of Technology community were given a candy bar to rate the completeness of the preamble of each sentence, which included the initial clause and the argument/ adjunct continuation. Two master lists were created for both nouns and verbs. Each list included the argument and adjunct variation of the noun or verb, resulting in 64 items. These items were used to create two randomized lists. The order of pages was randomized for each participant. Forty participants completed the verb list. The other 40 participants completed the noun list. The nouns and verbs were presented in separate lists because, intuitively, the requirements for completing the verbs and nouns seemed to differ. Specifically, the argument-taking verbs in our items (e.g., "denounced") require an NP argument, whereas the adjunct-taking verbs (e.g., "complained") do not require any following dependent head. In contrast, neither the argument-taking nouns nor the adjunct-taking nouns intuitively require a following dependent phrase of any kind. Thus, if we had included both nouns and verbs in the same list, differences between the completeness ratings of the nouns may have been reduced.

Each item was presented as a sentence fragment with the argument/ adjunct continuation in parentheses (e.g., The reporter investigated [the crash]/The reporter's arrival [after the crash]). Using a scale ranging from 1 (very complete) to 7 (very incomplete), we asked the participants to rate how completely the phrase without the parenthetical material described an event. The instructions included the following example phrases: The man placed (the apple on the table)/The man's placing (the apple on the table) and The dog slept (for an hour)/The dog's sleeping (for an hour). Participants were instructed that the first example would likely receive a 6 or 7 rating because The man placed (or The man's placing) is not a complete description without the material in parentheses. Furthermore, participants were advised that the second example would likely receive a 1 or 2 rating because The dog slept (or The dog's sleeping) describes an event well without the parenthetical material.

We later noticed that in examples such as The dog's sleeping, the word "dog's" is ambiguous between a genitive-marked NP (the intended meaning) or as a reduced copula form (as in The dog is sleeping). Although it is possible that participants interpreted the apostrophe-s form as a reduced copula in examples like these, ambiguous gerund forms like these were used in only 8 of the 64 items (see Appendix).

\section{Results}

For analysis purposes, trials were excluded from analyses when (a) the speaker answered both questions about a trial incorrectly (16 of 768 total trials) or (b) the listener answered his/her question about a trial sentence incorrectly (18 of 768 total trials). In addition, sentences with disfluencies-such as word repetitions, mispronunciations, and hesitation pauses - were also excluded from analysis (62 of the 768 total trials, 4 overlapping with trials for which questions were answered incorrectly). Although these trials were omitted from the analyses below, including them has no effect on the statistical patterns. In addition, one pair of participants was replaced because of the speaker's high percentage of disfluencies.

The percentages of intonational boundaries following the critical heads are displayed for each of the conditions in Figure 1. Overall, there was a main effect of part of speech, $F_{1}(1,23)=$ $22.42, p<.001 ; F_{2}(1,31)=26.80, p<.001$, with more intonational boundaries following nouns than verbs. ${ }^{8}$ There was also a

\footnotetext{
${ }^{8}$ Because trials with disfluencies and incorrect responses were excluded, there was one missing cell in the analyses of the items. This cell was filled in with the average for the condition.
} 
main effect of argumenthood, with more boundaries following adjuncts than arguments, $F_{1}(1,23)=35.80, p<.001 ; F_{2}(1,28)=$ $53.89, p<.001$. There was no interaction between part of speech and argumenthood $\left(F_{\mathrm{S}}<1\right)$, and there was no main effect of length, but there was a three-way interaction of argumenthood, part of speech, and length, $F_{1}(1,23)=11.34, p<.01 ; F_{2}(1,28)=$ $7.57, p<.01$.

Within the verb conditions, the greatest effect was by dependency type, with intonational boundaries occurring more frequently before adjuncts than arguments, $F_{1}(1,23)=30.57, p<$ $.001 ; F_{2}(1,31)=32.01, p<.001$. There was also a main effect of length that was significant by participants, $F_{1}(1,23)=5.25, p<$ .05 , but not significant by items, $F_{2}(1,31)=2.70, p=.11$. Finally, there was an interaction between length and dependency type, $F_{1}(1,23)=8.21, p<.01 ; F_{2}(1,31)=4.28, p<.05$. An inspection of Figure 1 suggests that the main effect of length in the subjects' analyses was driven by the interaction between length and dependency type. A planned comparison revealed that intonational boundaries occurred more often before long adjuncts than short adjuncts, $F_{1}(1,23)=7.63, p<.05 ; F_{2}(1,31)=4.23, p<$ .05 , but there was no difference between long arguments and short arguments $(F \mathrm{~s}<1)$.

Within the noun conditions, adjuncts were preceded by an intonational boundary more often than arguments, $F_{1}(1,23)=$ $18.84, p<.001 ; F_{2}(1,31)=19.70, p<.001$. There was no effect of length $\left(F_{\mathrm{S}}<1\right)$, but there was an interaction between length and dependency type that was significant in the participants analysis, $F_{1}(1,23)=6.83, p<.05$, and marginally significant in the items analysis, $F_{2}(1,31)=3.24, p=.08$. Planned comparisons revealed effects of length within the argument conditions that were significant by participants, $F_{1}(1,23)=4.99, p<.05$, and marginal by items, $F_{2}(1,31)=4.10, p=.05$. There was no effect of length within the adjunct condition $(F \mathrm{~s}<1)$, but the high percentage of intonational boundaries that occurred in adjunct conditions for both the long and the short constituent conditions suggests that the lack of a difference may be due to a ceiling effect.

The main effects of argumenthood and part of speech suggest that speakers are more likely to place boundaries before adjuncts than arguments and after nouns than verbs. In addition, these data also suggest that the obligatoriness of a dependent plays a critical role in boundary placement. Although there was no interaction between part of speech and argumenthood, the three-way interaction among the three factors provides support for the obligatoriness hypothesis. In particular, when an argument followed a verb (and was therefore obligatory), the length of the argument had no effect on the likelihood of the boundary. However, when an argument followed a noun - a case in which the argument was not obligatory-length did have an effect: Longer constituents were preceded by more intonational boundaries than shorter constituents, up to a ceiling effect of likelihood in producing a boundary.

Measurements of boundary placement before the lexical head suggest that boundaries at this location were not driving the results presented above. Boundary placement before the lexical head is shown in Figure 2.

An analysis of variance conducted on the three factors revealed two main effects. First, there was an effect of length such that more intonational boundaries occurred before the head in the short condition than in the long condition, $F_{1}(1,23)=6.98, p<.05$; $F_{2}(1,31)=4.36, p<.05$. Second, more boundaries occurred in the argument condition than in the adjunct condition, $F_{1}(1,23)=$ $7.64, p<.05 ; F_{2}(1,31)=4.22, p<.05$. Crucially, there were no interactions. Finally, although the placement of a boundary before the head was significantly correlated with the placement of a boundary after the head $\left(n=697, r^{2}=.02, p<.0001\right)$, this

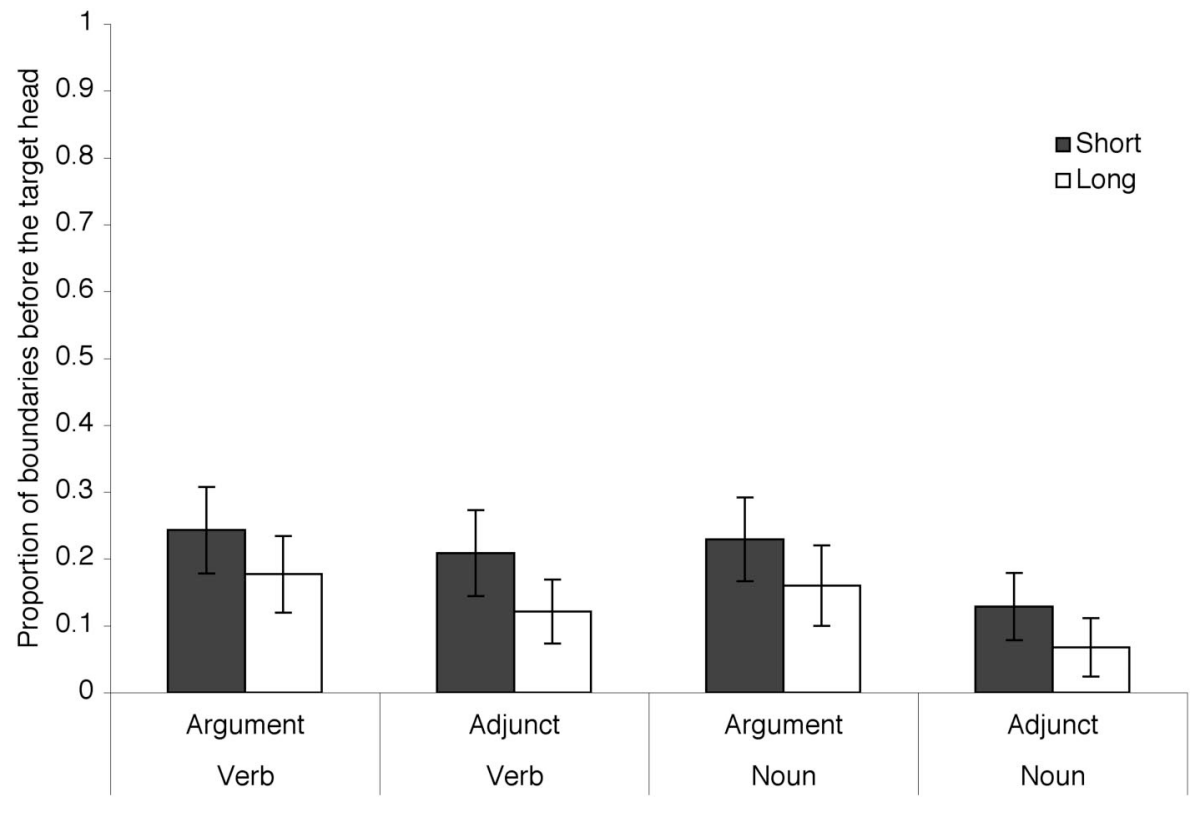

Figure 2. The proportion of intonational boundaries that immediately preceded the head verb/noun when the dependent of the head was an argument or adjunct. Error bars indicate the standard error of the mean. 
Table 1

The Average Ratings for the Completeness Survey on a Scale Ranging From 1 (complete) to 7 (incomplete)

\begin{tabular}{lcc}
\hline Variable & Nouns & Verbs \\
\hline Arguments & $4.30(.10)$ & $4.99(.11)$ \\
Adjuncts & $3.43(.10)$ & $2.11(.06)$ \\
\hline
\end{tabular}

Note. Standard errors are presented in parentheses.

correlation accounted for a very small quantity of variance, suggesting a weak correlation.

To investigate the degree to which obligatoriness was playing a role in the placement of intonational boundaries at the target posthead location, we conducted an analysis to search for potential correlations between (a) the likelihood of producing an intonational boundary at that location for a given item and (b) the rating of that item from the results of the item-completeness survey discussed above. If obligatoriness is a factor in producing intonational boundaries (as suggested by the analyses presented thus far), then intonational boundaries should occur more frequently after heads that are rated as more complete than after heads that are rated as less complete.

The results from the survey are presented in Table 1. There was a significant main effect of argumenthood, with arguments and their heads receiving a higher completeness rating than adjuncts and their heads, $F_{1}(1,81)=171.85, p<.001 ; F_{2}(1,31)=348.91$, $p<.001$. Because the nouns and verbs were entirely different sets of materials, and were presented to different sets of subjects, a comparison between these two sets would not be informative.
Overall, there was a significant inverse correlation between completeness and intonational boundary placement $\left(n=128, r^{2}=\right.$ $.14, p<.0001)$, but this was driven by a correlation within the verb condition $\left(n=64, r^{2}=.36, p<.0001\right)$. The correlation was not quite significant in the noun conditions $\left(n=64, r^{2}=.05, p=\right.$ .07). The high correlation within the verb condition is probably due to the existence of a categorical distinction between obligatory and nonobligatory dependents of the verb: arguments and adjuncts, as reflected in the clear bimodal distribution in the verb condition in the scatter plot in Figure 3. In contrast, the scatter plot in Figure 4 shows no such distribution within the noun condition, which is consistent with the nonobligatory nature of noun dependents.

\section{Discussion}

Overall, the data suggest that there is some validity to all three of the hypotheses. Speakers are more likely to place boundaries after nouns than verbs, and they are less likely to place boundaries after arguments than adjuncts. These data also suggest that boundaries are generally not produced between heads and their immediately following obligatory argument dependents but are produced between heads and their optional dependents. More generally, it may be that the likelihood of producing a boundary between a head and an immediately following dependent of that head is affected by the obligatoriness of the dependent constituent type, such that the more obligatory a constituent is - as measured in, for example, corpus frequencies or sentence continuation norms - the smaller the likelihood that a boundary will be produced before it. Furthermore, the data presented here also suggest that the likelihood of producing an intonational boundary between a word and an immediately following optional dependent of that

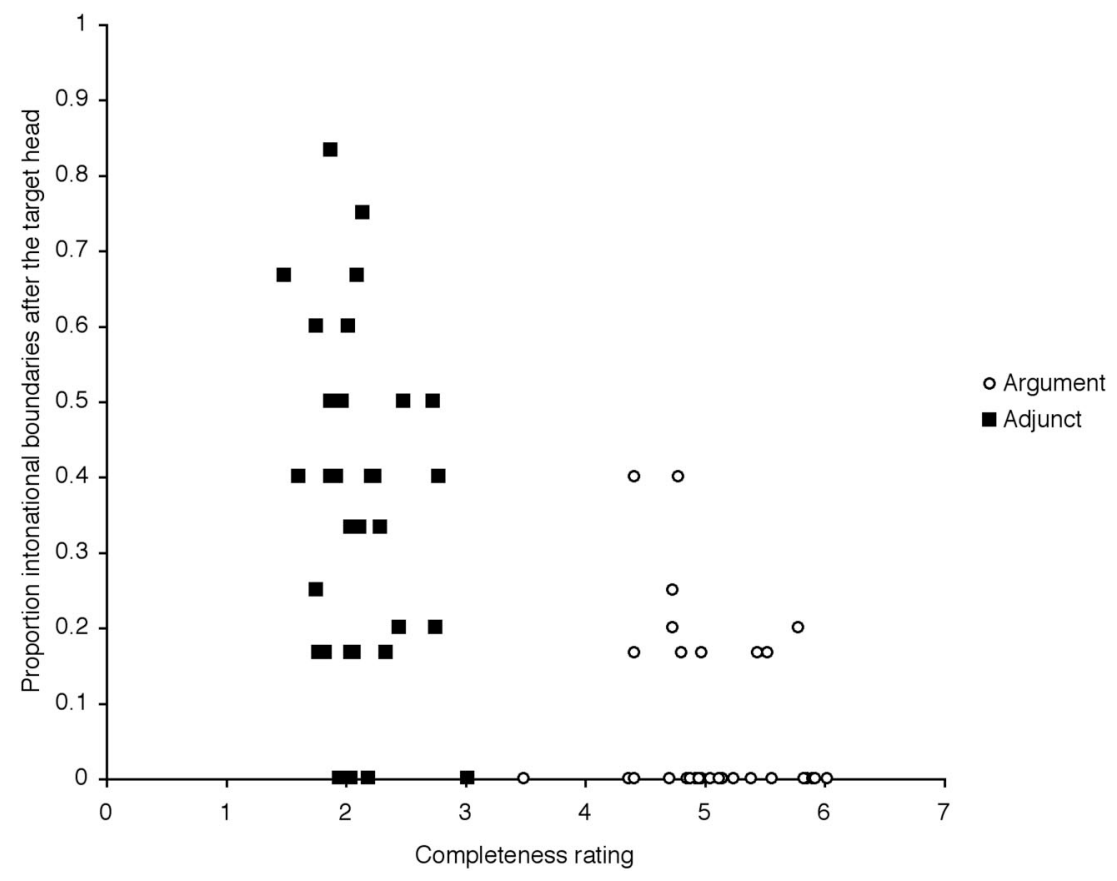

Figure 3. The proportion of intonational boundaries versus completeness ratings within the verb conditions. 


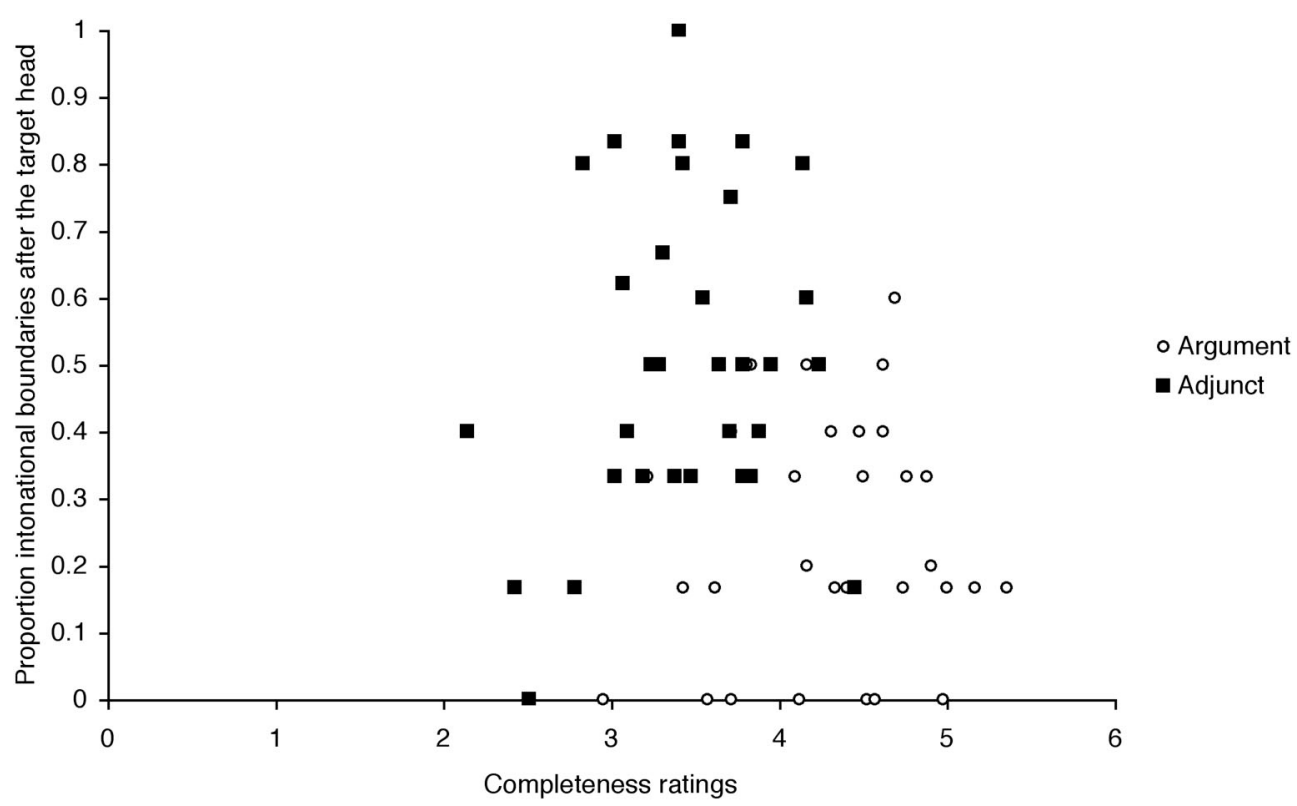

Figure 4. The proportion of intonational boundaries versus completeness ratings within the noun conditions.

word is affected by the length of the dependent constituent, such that the longer the dependent constituent is, the greater the likelihood for a boundary.

Watson and Gibson's (2004) hypothesis - that upcoming constituent length is a factor in predicting the likelihood of an intonational boundary when the constituent is not an argument of the most recently produced lexical head-was on the right track but must be revised. In particular, heads and arguments are not bound together in production, as Watson and Gibson proposed. Rather, it appears that heads and their obligatory (argument) dependents are bound together in production such that they overpower length effects. In addition, part of speech and argumenthood may also play a role in boundary placement to the extent that they reflect the closeness of linguistic elements that are planned together. Ultimately, finding ways to quantify linguistic closeness, such as corpus searches and/or completeness norms, may provide clues to understanding how all of these factors interact to influence intonational phrasing.

It is important to note that our claim is not that intonational phrasing is only a product of planning linguistically close elements. It is likely that a number of other factors also contribute to the placement of intonational boundaries, including discourse structure or rhythm of speech, among others. For example, F. Ferreira and Swets (2002) have argued that planning units may be under some degree of top-down control, which might override effects of linguistic closeness. Similarly, research has shown that shorter, less syntactically complex elements tend to be produced earlier in a sentence (e.g., Arnold, Wasow, Losongco, and Ginstrom, 2000). Producing entities that are shorter or highly accessible early on in a sentence may negate requirements for producing an intonational phrase boundary before information that is long or not accessible because speakers no longer require extra time. It is clear that there is a great deal of work to be done in exploring the interaction between intonational phrase boundaries and production and that this is only a first step.

In addition to providing data that are potentially informative to the nature of head-dependent closeness in production, the results of this experiment also clearly demonstrate the importance of lexical information (e.g., a word's requirement to be followed by an obligatory dependent) in intonational phrase boundary placement. These lexical effects help distinguish a production-based theory of intonational boundary placement (as proposed by Watson \& Gibson, 2004) from a comprehensionbased theory. According to a comprehension-based theory, the distribution of intonational boundaries should be driven by the needs of the listener, such that the presence or absence of a boundary conveys syntactic or semantic information to the listener. Thus, a prediction of the comprehension-based theory is that there should be no modulation in boundary production following a head depending on the lexical requirements of the head, because after the head has been produced, the boundary is no longer informative to the listener. In contrast to the predictions of the comprehension-based theory, the data from the current experiment support Watson and Gibson's (2004) contention that speakers place intonational boundaries where they do for their own processing needs. In particular, it was found that boundary placement following a head was indirectly modulated by the lexical requirements (i.e., argument structure obligatoriness) of the head. Lexical influences on boundary placement are therefore more consistent with a model of production in which speakers produce boundaries for their own processing needs.

These results also suggest that intonational phrase boundaries are a useful tool in understanding the timing processes in language production. One of the major obstacles to understanding processes in production is the limited inventory of tools available to inves- 
tigate speech. The distribution of intonational phrase boundaries may be as useful as the distribution of speech errors in studying the mechanisms underlying language production.

\section{References}

Arnold, J. E., Wasow, T., Losongco, T., \& Ginstrom, R. (2000). Heaviness vs. newness: The effects of structural complexity and discourse status on constituent ordering. Language, 76, 28-55.

Beckman, M. E., \& Pierrehumbert. (1986). Intonational structure in Japanese and English. Phonology Yearbook, 3, 255-309.

Bock, K., \& Levelt, W. J. M. (1994). Language production: Grammatical encoding. In M. A. Gernsbacher (Ed.), Handbook of psycholinguistics (pp. 945-984). London: Academic Press.

Cooper, W. E., \& Paccia-Cooper, J. (1980). Syntax and speech. Cambridge, MA: Harvard University Press.

Cutler, A., Dahan, D., \& Van Donselaar, W. A. (1997). Prosody in the comprehension of spoken language: A literature review. Language and Speech, 40, 141-202.

Ferreira, F. (1988). Planning and timing in sentence production: The syntax-to-phonology conversion. Unpublished doctoral dissertation, University of Massachusetts, Amherst.

Ferreira, F. (1991). Effects of length and syntactic complexity on initiation times for prepared utterances. Journal of Memory and Language, 30 , 210-233.

Ferreira, F. (1993). Creation of prosody during sentence production. Psychological Review, 100, 233-253.

Ferreira, F., \& Swets, B. (2002). How incremental is language production? Evidence from the production of utterances requiring the computation of arithmetic sums. Journal of Memory and Language, 46, 57-84.

Ferreira, V. S. (1996). Is it better to give than to donate? Syntactic flexibility in language production. Journal of Memory and Language, $35,724-755$.

Ford, M. (1982). Sentence planning units: Implications for the speaker's representation of meaningful relations underlying sentences. In J. Bresnan (Ed.), The mental representation of grammatical relations (pp. 797-827). Cambridge, MA: MIT Press.

Frazier, L., Clifton, C., \& Carlson, K. (2004). Don't break or do: Prosodic boundary preferences. Lingua, 114, 3-27.

Garrett, M. F. (1976). Syntactic processes in sentence production. In G. H.
Bower (Ed.), New approaches to language mechanisms (pp. 177-220). London: Academic Press.

Gee, J. P., \& Grosjean, F. (1983). Performance structures. A psycholinguistic and linguistic appraisal. Cognitive Psychology, 15, 411-458.

Grimshaw, J. (1990). Argument structure. Cambridge, MA: Cambridge Press.

Holmes, V. M. (1988). Hesitations and sentence planning. Language and Cognitive Processes, 3, 323-361.

Jackendoff, R. (1977). X-bar syntax: A study of phrase structure. Cambridge, MA: MIT Press.

Levelt, W. (1989). Speaking: From intention to articulation. Cambridge, MA: MIT Press.

Meyer, A. S. (1996). Lexical access in phrase and sentence production: Results from picture-word interference experiments. Journal of Memory and Language, 35, 477-496.

Nespor, M., \& Vogel, I. (1986). Prosodic phonology. Dordrecht, the Netherlands: Foris Publications.

Pitrelli, J., Beckman, M., \& Hirschberg, J. (1994). Evaluation of prosodic transcription labeling reliability in the ToBI framework. Proceedings of the 1994 International Conference on Spoken Language Processing, 1, 123-126.

Schafer, A. J. (1997). Prosodic parsing: The role of prosody in sentence comprehension. Unpublished doctoral dissertation, University of Massachusetts, Amherst.

Schütze, C., \& Gibson, E. (1999). Argumenthood and English prepositional phrase attachment. Journal of Memory and Language, 40, 409431.

Selkirk, E. O. (1984). The relation between sound and structure. Cambridge, MA: MIT Press.

Shattuck-Hufnagel, S., \& Turk, A. E. (1996). A prosody tutorial for investigators of auditory sentence processing. Journal of Psycholinguistic Research, 25, 193-247.

Solomon, E. S., \& Pearlmutter, N. J. (2004). Semantic integration and syntactic planning in language production. Cognitive Psychology, 49, $1-46$.

Watson, D., \& Gibson, E. (2004). The relationship between intonational phrasing and syntactic structure in language production. Language and Cognitive Processes, 19, 713-755.

Wheeldon, L., \& Lahiri, A. (1997). Prosodic units in speech production. Journal of Memory and Language, 37, 356-381. 


\section{Appendix}

\section{Experimental Materials}

The materials that were used in the experiment are presented below. The verb and noun conditions are presented in their entirety for all items. To generate the argument conditions for the verb conditions, take the first verb (e.g., opposed in [2]). To generate the adjunct conditions for the verb conditions, take the second verb plus the following preposition (e.g., disappeared before in [2]). To generate the argument conditions for the noun conditions, take the first noun plus the following preposition (e.g., opposition to in [2]). To generate the adjunct conditions for the noun conditions, take the second noun plus the following preposition (e.g., disappearance before in [2]). The short versions of each item are formed by omitting the prepositional phrase in parentheses (e.g., of the Concorde in [2]). The long versions are formed by including this prepositional phrase.

1. VERB

a. Argument, short:

The reporter investigated the crash and this unnerved the officials.

b. Argument, long:

The reporter investigated the crash of the subway and this unnerved the officials.

c. Adjunct, short:

The reporter arrived after the crash and this unnerved the officials.

d. Adjunct, long

The reporter arrived after the crash of the subway and this unnerved the officials.

1. NOUN

e. Argument, short:

The reporter's investigation of the crash unnerved the officials.

f. Argument, long:

The reporter's investigation of the crash of the subway unnerved the officials.

g. Adjunct, short:

The reporter's arrival after the crash unnerved the officials.

h. Adjunct, long:

The reporter's arrival after the crash of the subway unnerved the officials.

2. VERB

The pilot opposed/disappeared before the takeoff (of the Concorde) and this annoyed the passengers.

2. NOUN

The pilot's opposition to/disappearance before the takeoff (of the Concorde) annoyed the passengers.

3. VERB

The wimp challenged/boasted near the bully (from sixth grade) and this startled his classmates.

3. NOUN

The wimp's challenge of/boast near the bully (from sixth grade) startled his classmates.

4. VERB

The vagrant robbed/collapsed near the store (in the mall) and this scared the merchants.

4. NOUN

The vagrant's robbery of/collapse near the store (in the mall) scared the merchants.

5. VERB

The comedian ridiculed/spoke before the senator (from North Carolina) and this amused the audience.

5. NOUN

The comedian's ridicule of/speech before the senator (from North Carolina) amused the audience.

\section{VERB}

The critic denounced/complained after the movie (for young children) and this outraged the producers.

6. NOUN

The critic's denouncement of/complaining after the movie (for young children) outraged the producers.

7. VERB

The bully threatened/swore during the class (of second graders) and this frightened the children.

7. NOUN

The bully's threatening of/swearing during the class (of second graders) frightened the children.

\section{VERB}

The committee reversed/wavered after the decision (on global warming) and this inflamed the protesters.

8. NOUN

The committee's reversal of/wavering after the decision (on global warming) inflamed the protesters.

9. VERB

The examiner postponed/chuckled during the interview (for graduate school) and this distressed the candidate.

9. NOUN

The examiner's postponement of/chuckle during the interview (for graduate school) distressed the candidate.

10. VERB

The bull pursued/snarled near the toreador (from Northern Spain) and this entertained the spectators.

10. NOUN

The bull's pursuit of/snarl near the toreador (from Northern Spain) entertained the spectators.

11. VERB

The guard harassed/smirked behind the prisoner (on death row) and this disturbed the public.

11. NOUN

The guard's harassment of/smirk behind the prisoner (on death row) disturbed the public.

12. VERB

The athlete neglected/winced after his injury (in the knee) and this concerned the fans.

12. NOUN

The athlete's neglect of/wince after his injury (in the knee) concerned the fans.

13. VERB

The mother attended/spoke during the funeral (of her child) and this moved the onlookers.

13. NOUN

The mother's attendance of/speech during the funeral (of her child) moved the onlookers.

14. VERB

The defendant disregarded/laughed in the court (of tax appeals) and this upset the judge.

14. NOUN

The defendant's disregard of/laugh in the court (of tax appeals) upset the judge.

15. VERB

The insect ate/crawled near the fruit (in the window display) and this disgusted the customer.

15. NOUN 
The insect's eating of/crawling near the fruit (in the window display) disgusted the customer.

\section{VERB}

The millionaire attended/assented after the meeting (on global expansion) and this satisfied the entrepreneur.

16. NOUN

The millionaire's attendance of/assent after the meeting (on global expansion) satisfied the entrepreneur.

17. VERB

The viewers boycotted/complained after the sitcom (on homosexual relationships) and this distressed the producers.

17. NOUN

The viewers' boycott of/complaining after the sitcom (on homosexual relationships) distressed the producers.

18. VERB

The waiter disliked/scowled behind the customer (by the front window) and this worried the maitre d'.

18. NOUN

The waiter's dislike of/scowl behind the customer (by the front window) worried the maitre d'.

19. VERB

The prosecutor badgered/shouted beside the witness (from Big Tobacco) and this engrossed the jury.

19. NOUN

The prosecutor's badgering of/shout beside the witness (from Big Tobacco) engrossed the jury.

20. VERB

The child broke/hid behind the statue (of John Kennedy) and this embarrassed his mother.

20. NOUN

The child's breaking of/hiding behind the statue (of John Kennedy) embarrassed his mother.

21. VERB

The jock crashed/arrived during the party (for new sisters) and this aggravated the sorority.

21. NOUN

The jock's crashing of/arrival during the party (for new sisters) aggravated the sorority.

22. VERB

The protestors denounced/chanted near the monument (in the plaza) and this angered the president.

\section{NOUN}

The protestors' denouncement of/chant near the statute (in the plaza) angered the president.

\section{VERB}

The teacher choreographed/bowed after the performance (of the Christmas pageant) and this pleased the parents.

23. NOUN

The teacher's choreography of/bow after the performance (of the Christmas pageant) pleased the parents.

24. VERB

The kitten licked/purred near the children (of the owners) and this delighted the onlookers.

24. NOUN
The kitten's licking of/purring near the children (of the owners) delighted the onlookers.

25. VERB

The baby grabbed/cooed after the bottle (of warm milk) and this awed the parents.

25. NOUN

The baby's grab at/coo after the bottle (of warm milk) awed the parents. 26. VERB

The father ridiculed/slept during the play (about American Independence) and this upset the mother.

26. NOUN

The father's ridicule of/sleeping during the play (about American Independence) upset the mother.

27. VERB

The boyfriend criticized/burped after the meal (of filet mignon) and this disturbed his girlfriend.

27. NOUN

The boyfriend's criticism of/burp after the meal (of filet mignon) disturbed his girlfriend.

28. VERB

The carnivore consumed/grinned after his dinner (of rare steak) and this repulsed the vegetarian.

28. NOUN

The carnivore's consumption of/grin after his dinner (of rare steak) repulsed the vegetarian.

29. VERB

The citizens criticized/marched before the election (of vice president) and this concerned the candidate.

29. NOUN

The citizens' criticism of/march before the election (of vice president) concerned the candidate.

30. VERB

The jet destroyed/crashed near the museum (of Natural History) and this devastated the public.

30. NOUN

The jet's destruction of/crash near the museum (of Natural History) devastated the public.

31. VERB

The hero rescued/dueled before the princess (of Spanish decent) and this delighted the children.

31. NOUN

The hero's rescue of/duel before the princess (of Spanish descent) delighted the children.

32. VERB

The addict lost/smoked behind his house (in New Jersey) and this angered his wife.

32. NOUN

The addict's loss of/smoking behind his house (in New Jersey) angered his wife.

Received January 28, 2005

Revision received October 26, 2005

Accepted November 2, 2005 